\title{
Recurrent T Acute Lymphoblastic Leukemia
}

National Cancer Institute

\section{Source}

National Cancer Institute. Recurrent T Acute Lymphoblastic Leukemia. NCI Thesaurus.

Code C150131.

The reemergence of $\mathrm{T}$ acute lymphoblastic leukemia after a period of remission. 